\title{
Lignin-First Biorefining of Lignocellulose: the Impact of Process Severity on the Uniformity of Lignin Oil Composition
}

\author{
Roberto Rinaldi, ${ }^{\oplus *, a}$ Robert T. Woodward, ${ }^{a}$ Paola Ferrini ${ }^{b, c}$ and Hebert J. E. Rivera ${ }^{c}$ \\ ${ }^{a}$ Department of Chemical Engineering, Imperial College London, South Kensington Campus, \\ SW7 2AZ London, United Kingdom
}

${ }^{b}$ Department of Chemistry, Imperial College London, White Campus, W12 OBZ London, United Kingdom

${ }^{c}$ Max-Planck-Institut für Kohlenforschung, Kaiser-Wilhelm-Platz 1, 45470 Mülheim an der Ruhr, Germany

\begin{abstract}
In lignin-first biorefining via reductive processes, lignocellulosic materials are deconstructed by the solvent extraction of lignin in the presence of a hydrogenation catalyst. This approach provides a route to the successful extraction and reductive passivation of lignin fragments to produce low molar mass lignin oils together with high-quality pulps. Herein, we present an investigation into the impact of process severity (i.e., cooking temperature) on the reductive processes taking place on the lignin fragments and uniformity of the product mixture. In addition to improving overall delignification yields (up to $87 \%$ ) and producing low molar mass fragments, higher process temperatures led to the preferential cleavage of hydroxyl groups in monolignol sidechains via hydrodeoxygenation, yielding oils with lower oxygen content. By comparing products from both lignin-first biorefining and organosolv processes at various temperatures, we elucidate key performance differences and outline routes to increased chemical uniformity in lignin streams. Overall, this study outlines clearly the importance of process temperature in the deconstruction of lignocellulose by lignin-first biorefining when producing highly depolymerized lignin products. This study points out a trade-off in the effect of temperature upon delignification and increase in product mixture complexity, which needs to be carefully optimized for the scale-up of lignin-first technologies.
\end{abstract}

Keywords: lignin, lignin-first biorefining, Raney Ni, hydrogen-transfer, catalysis

\section{Introduction}

The utilization of lignin via depolymerization holds potential to provide numerous aromatic building blocks. ${ }^{1-4}$ However, unlike cellulose depolymerization, which can selectively produce glucose at high yields, ${ }^{5}$ the breakdown of technical lignins (e.g., kraft, soda, and lignosulfonates) is problematic as it typically generates a variety of products at very low individual yields $(<1 \%)$ in addition to chars. ${ }^{6,7}$ Considering lignin's depolymerization products, besides the unique pattern of methoxylation on the ortho-positions, the products will also present much richer functionalization on the para-position, in their $\mathrm{C}_{1}-\mathrm{C}_{3}$ alkyl chains. Such functionalized aromatics from lignin are currently too expensive to produce via petrochemical routes due to challenges in the selective oxidation of aromatic hydrocarbons. ${ }^{8}$ However, when obtained at low individual yield by lignin depolymerization, such a wealth of value-added products loses its value, owing to difficulties,

*e-mail: rrinaldi@ic.ac.uk which inevitably will be encountered in their separation and purification. Therefore, the design of new methods for the rational deconstruction of lignocellulose, preventing the generation of lignin recalcitrance and targeting a decrease in the complexity of lignin's low molar mass $\left(\mathrm{M}_{\mathrm{w}}\right)$ product mixtures, represents a timely challenge to tackle.

Recently, we applied the early-stage catalytic conversion of lignin (ECCL) via reductive processes to the deconstruction of lignocellulose. ${ }^{1,3}$ Through catalytic $\mathrm{H}$-transfer reactions, the biorefining process resulted in the isolation of depolymerized lignin streams (lignin oil) in addition to high-quality pulps. Compared with organosolv lignin, the lignin oil is highly susceptible to further hydrodeoxygenation (HDO) under low-severity conditions. Therefore, the previous experience demonstrated the use of a hydrogenation catalyst in the lignocellulose deconstruction to establish a unique platform for lignin valorization. ${ }^{1}$ Importantly, such biorefining processes are not detrimental to the valorization of the cellulose stream, as will be discussed later. Considering the potential of the catalytic biorefining processes designed from the 
perspective of lignin utilization, this biorefining strategy became known as lignin-first biorefining. ${ }^{1,3}$ Currently, lignin-first biorefining has also been referred to as catalytic upstream biorefining (CUB) and reductive catalytic fractionation (RCF). ${ }^{1,2,9-19}$

ECCL improves the lignocellulose deconstruction owing to selective HDO of lignin fragments (Hibbert's ketones (HK) or HK-bound polymers), which converts both ketone and aldehyde functionalities into methylene and methyl groups, respectively. ${ }^{3}$ In this manner, the selective HDO of HK side-chains removes the functional groups that would be otherwise involved in the recondensation of lignin species via electrophilic aromatic substitution and other $\mathrm{C}-\mathrm{C}$ forming reactions. ${ }^{20} \mathrm{As}$ recondensation is circumvented, the isolated lignin fraction is obtained as a viscous oil comprising variable fraction of compounds of low molar mass (100-600 Da), with a high content of individual components. Therefore, unlike conventional approaches for the deconstruction of plant biomass, ligninfirst biorefining processes can also be described as a process preventing the generation of lignin recalcitrance, providing a platform for the production of several valuable materials, such as high-energy-density drop-in fuels. ${ }^{21}$

Scheme 1 displays a general overview of the workflow of the CUB process. Initially, lignocellulose and Raney $\mathrm{Ni}$ (hydrogenation catalyst) are suspended in an aqueous solution of 2-propanol (2-PrOH: $\mathrm{H}_{2} \mathrm{O}, 7: 3$, v/v) and heated under mechanical stirring. This solution serves both as a lignin-extracting liquor and as an $\mathrm{H}$-source, since 2-PrOH acts as an $\mathrm{H}$-donor in the presence of Raney $\mathrm{Ni}^{20}{ }^{20}$ The pulp (i.e., cellulose and hemicellulose) is isolated by filtration and washed with 2-PrOH/water solution. Raney $\mathrm{Ni}$ is easily removed from the suspension using a magnet, allowing for efficient recycling. ${ }^{1,22}$ Finally, the deconstructed lignin oil is isolated by solvent removal.

Recently, the implications of the reductive processes catalyzed by Raney Ni for the pulp composition, degree of polymerization and morphology, were examined in detail. ${ }^{22}$ Clearly, as there are negligible points of contact between the surfaces of Poplar wood chips and Raney $\mathrm{Ni}$, the catalyst activity is limited to the soluble species (leached from the lignocellulosic substrate into the liquor) that are capable of interacting with the Raney Ni surface via adsorption. From the pulp composition's perspective, by the passivation of lignin fragments dissolved in the liquor, the recondensation of lignin onto the detachinglignin on pulp's fibers is mitigated. As a result, ligninfirst biorefining usually achieves a delignification higher than that by organosolv processes. ${ }^{22,23}$ Moreover, as hemicellulose sugars will invariably be formed as a result of solvolytic processes, reductive processes on hemicellulose sugars rendering sugar alcohols also play a key role in the pulp quality. The hydrogenation of hemicellulose sugars acts as an effective strategy to suppress the degradation of hemicellulose sugars, stopping the formation of formic acid. ${ }^{22,24}$ The reduction in the content of formic acid in the liquor is conducive for both high xylan retention and the production of cellulosic pulps with a high degree of polymerization, as recently reported by us. ${ }^{24}$

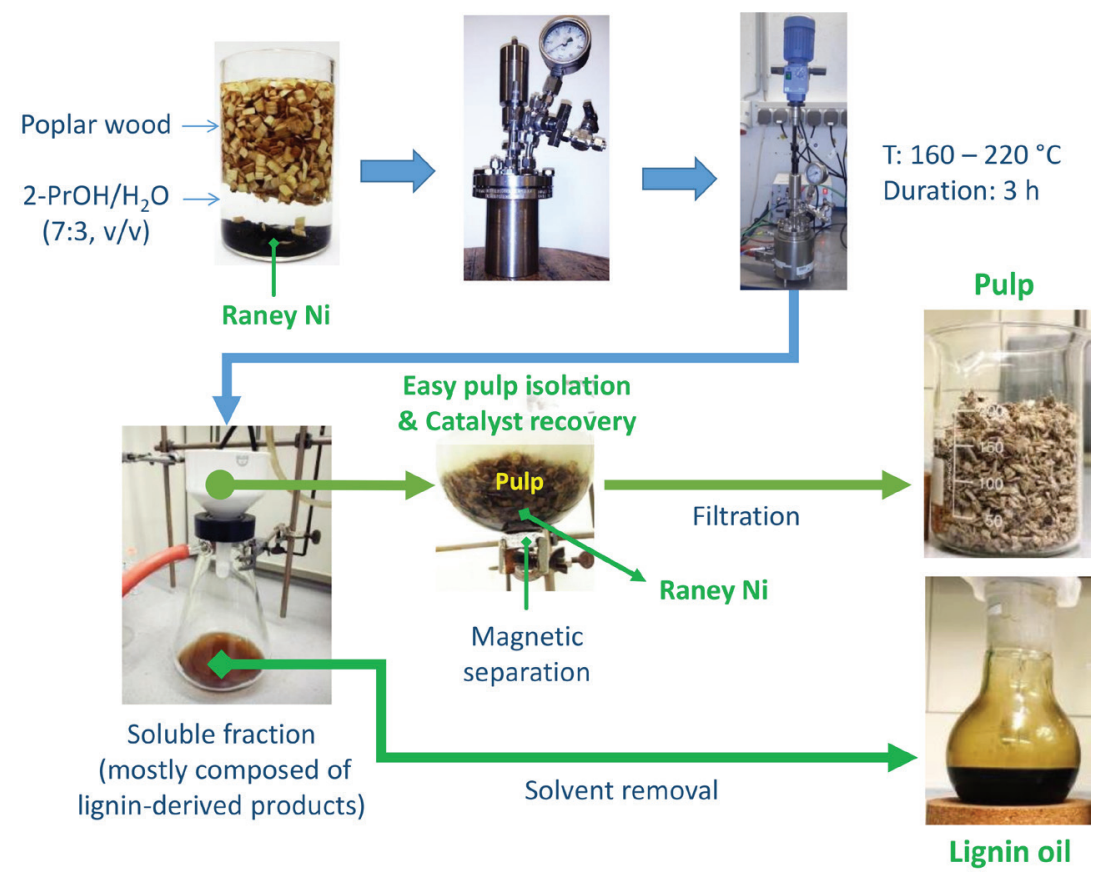

Scheme 1. Outline of the CUB method (adapted from Ferrini et al.).22 
Demonstrated by several research groups, lignin-first biorefining produces four distinct categories of lignin platform chemicals, depending on the process conditions and catalyst employed, as summarized in Scheme 2. Notably, the degree of functionalization of the propyl side chain $(\mathrm{R})$ of the lignin-derived phenolic products constitutes the feature distinguishing the catalytic systems already reported. In fact, dihydro-p-lignols ( $\mathrm{R}$ : $-\mathrm{CH}_{2} \mathrm{CH}_{2} \mathrm{CH}_{2} \mathrm{OH}$, Scheme $2, \mathbf{1}$ ) are the primary products of the $\mathrm{H}$-transfer CUB process performed in the presence of Raney $\mathrm{Ni}$ employing 2-propanol as part of the solvent system and also as the primary $\mathrm{H}$-donor for the reductive processes ${ }^{1,22,23}$ or $\mathrm{Pd} / \mathrm{C}$ catalyst under $\mathrm{H}_{2}$ pressures $(2 \mathrm{MPa}) .^{25} \mathrm{In}$ turn, dehydro- $p$-lignols $\left(\mathrm{R}:-\mathrm{CH}=\mathrm{CHCH}_{2} \mathrm{OH}\right.$, Scheme 2, 2) were reported for processes performed in the presence of Ni/C catalysts under low $\mathrm{H}_{2}$ pressures $(0.5 \mathrm{MPa}) .{ }^{13}$ Propenyl derivatives of lignols $\left(\mathrm{R}:-\mathrm{CH}=\mathrm{CHCH}_{3}\right.$, Scheme 2, 3) were reported as the main products from the lignin-first process carried out in the presence of $\mathrm{Pd} / \mathrm{C}$ under no $\mathrm{H}_{2}$ pressure ${ }^{26}$ or a $\mathrm{Ni} / \mathrm{C}$ catalytic system under low $\mathrm{H}_{2}$ pressure $(0.5 \mathrm{MPa}) .{ }^{13}$ Extensive $\mathrm{HDO}$ of the $\mathrm{C}_{3}$ side-chain, rendering 4-propylguaiacol and 4-propylsyringol ( $\mathrm{R}:-\mathrm{CH}_{2} \mathrm{CH}_{2} \mathrm{CH}_{3}$, Scheme 2,4$)$, is achieved in the presence of $\mathrm{Ru} / \mathrm{C}$ or $\mathrm{Zn}{ }^{\mathrm{II}} / \mathrm{Pd} / \mathrm{C}$ or even $\mathrm{Ni} / \mathrm{C}$ catalytic system under moderate $\mathrm{H}_{2}$ pressures (1-3.4 MPa). ${ }^{11-14,27}$

A deeper understanding of the impact of process severity (defined by temperature and time of lignocellulose cooking) upon the reductive processes taking place on the lignin fragments is essential to optimization and control

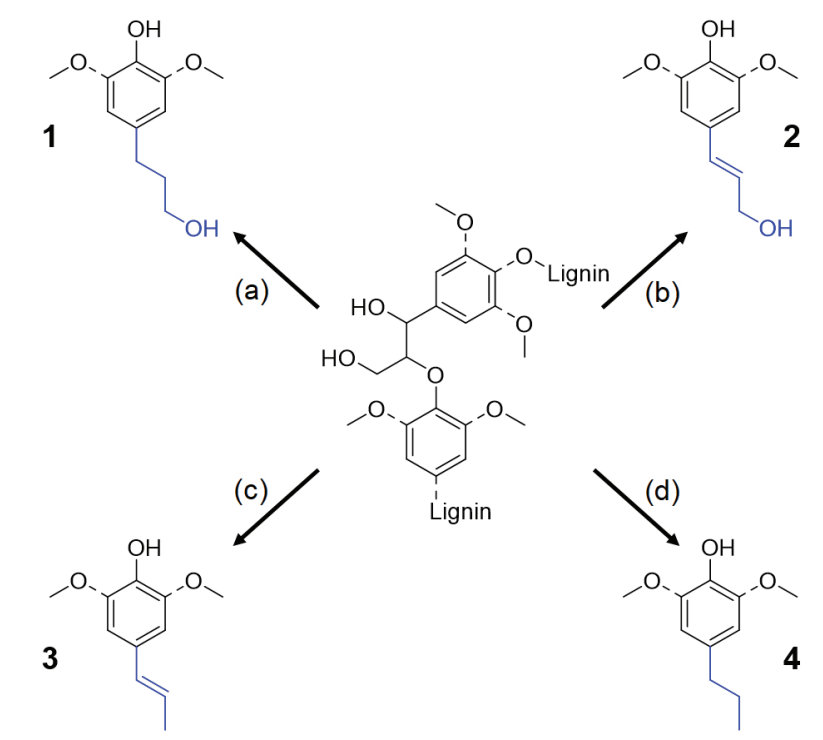

Scheme 2. Characteristic primary monophenol products obtained from lignin-first approaches in the presence of different hydrogenation catalysts under varied conditions. (a) Raney Ni employing 2-PrOH ${ }^{1,22,23}$ as $\mathrm{H}$-donor or $\mathrm{Pd} / \mathrm{C}, 2 \mathrm{MPa} \mathrm{H}_{2},{ }^{25}$ (b) $\mathrm{Ni} / \mathrm{C}, 0.5 \mathrm{MPa} \mathrm{H}_{2}$; $^{13}$ (c) $\mathrm{Pd} / \mathrm{C}$, no $\mathrm{H}_{2}$ pressure (internal H-transfer) ${ }^{26}$ or $\mathrm{Ni} / \mathrm{C}, 0.5 \mathrm{MPa} \mathrm{H}_{2},{ }^{13}$ and (d) $\mathrm{Ru} / \mathrm{C}$ or $\mathrm{Zn}{ }^{\mathrm{II}} \mathrm{Pd} / \mathrm{C}$ or $\mathrm{Ni} / \mathrm{C}$ under 1-3.4 $\mathrm{MPa} \mathrm{H}_{2}{ }^{11-14,27}$ over the product distribution obtained from lignin-first biorefining techniques. In the CUB process, 2-propanol is employed both as part of the lignin-extracting liquor and as an H-donor. Understandably, the content of transferablehydrogen available for reductive processes is primarily defined by the fraction of 2-PrOH present in the liquor. Nonetheless, the extent of HDO and its selectivity will also be dependent upon reaction temperature. Therefore, it is essential to establish whether increases in temperature would be beneficial or detrimental to 'chemical uniformity' of the lignin-product mixture.

Herein, the effect of process severity, as defined by the cooking temperature in the CUB process, is examined. This report is organized as follows: in the first section, the impact of increased process temperatures on both delignification extent and resulting pulp composition is investigated. Moreover, the effect of temperature on the chemical composition of both CUB and organosolv isolated lignins is described by using elemental analysis to obtain $\mathrm{H} / \mathrm{C}$ and $\mathrm{O} / \mathrm{C}$ molar ratios within the materials. It is important to note that organosolv experiments, i.e., processes carried out in the absence of Raney $\mathrm{Ni}$, are performed as control experiments, to allow for the deeper understanding of catalyst performance at various temperatures in CUB systems. Following this section, gel permeation chromatography (GPC) and heteronuclear single quantum coherence (HSQC) nuclear magnetic resonance (NMR) are employed in order to establish the effects of temperature on the polymeric fractions of the isolated lignin streams. Changes to the chemical functionality of lignins due to H-transfer hydrogenolysis of lignin's ether linkages are described, as well as the differences in molar mass, helping to elucidate the importance of process temperature. In the final section, the impact of temperature on the distribution of low molar mass products within CUB lignins is examined. Individual components of lignin oils are identified using two-dimensional gas chromatography $(\mathrm{GC} \times \mathrm{GC})$ and their relative ratios within different lignin oil samples are compared and discussed. Finally, fractionation of a CUB lignin oil by Kugelrohr distillation is performed to confirm the oils are composed primarily of discreet phenolic compounds.

\section{Results and Discussion}

Impact of temperature on the $\mathrm{H}$-content transferred into the lignin streams

The temperature of lignocellulose cooking has a profound impact on the quantity of soluble lignin, which will be released in the liquor for the ECCL. Therefore, 
before assessing the impact of temperature on the $\mathrm{H}$-content transferred into the lignin streams, it becomes necessary to consider the levels of delignification achieved by CUB and organosolv processes. Summarized in Table 1 are the key results obtained from the CUB and organosolv processes performed on Poplar wood at various temperatures.

For both CUB and organosolv processes, Table 1 shows that the quantities of soluble species (i.e., lignin fragments and hemicellulose sugars) released from Poplar increased with the process temperature. Nonetheless, it is clear that the quantity of soluble species released from Poplar wood by the organosolv process was higher than that from the CUB process. Recently, we found that this observation is associated with the higher content of acidic species in the organosolv liquor, compared to those of the CUB process. Both formic acid and acetic acid in the organosolv liquors bring about acid-catalyzed hydrolysis of hemicelluloses, which lowers the xylan content in the pulps upon the release of soluble oligosaccharides in the liquor. In this manner, a higher weight yield of a soluble fraction does not always translate into a greater pulp delignification. For the organosolv process performed at temperatures of $180^{\circ} \mathrm{C}$ or higher, delignification did not exceed $75 \pm 2 \%$, in agreement with previous reports on ethanol organosolv pulping of Poplar wood. ${ }^{28,29}$ Conversely, in the CUB the delignification steadily improved with the process temperature, achieving $87 \%$ in the pulp obtained from the treatment at $220^{\circ} \mathrm{C}$.

The utilization of 2-PrOH as the $\mathrm{H}$-donor produces acetone. In this manner, considering that there are no other reactions consuming 2-PrOH in CUB process, to determine the equivalent amount of $\mathrm{H}_{2}$ utilized as 2-PrOH by the CUB process at different temperatures, the content of acetone and 2-propanol in the liquor was determined by $\mathrm{GC}$ with a flame ionization detector (FID). Figure 1 shows the evolution of the acetone/2-PrOH molar ratio with the processes temperature.

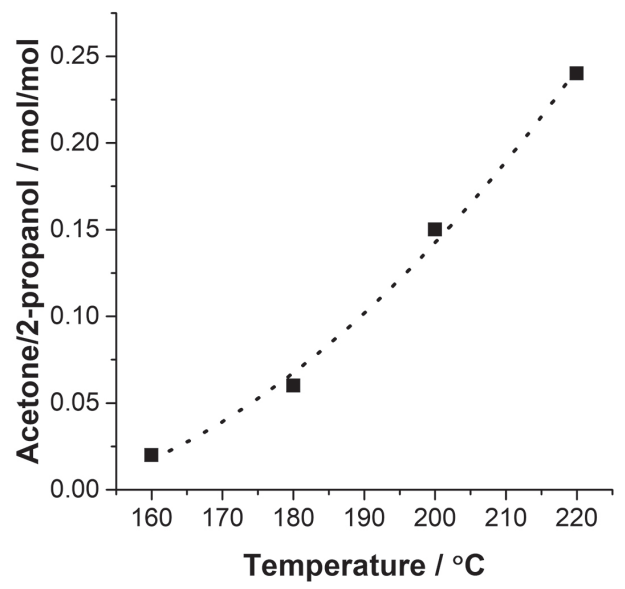

Figure 1. Effect of temperature on the $\mathrm{H}_{2}$ equivalent quantity consumed by the CUB process, as determined by the mole ratio of acetone/2-propanol found in the CUB liquor.

The quantity of $\mathrm{H}_{2}$-equivalent transferred from 2-PrOH to the lignocellulose soluble components increased by 12-times when the process temperature was increased from 160 to $220^{\circ} \mathrm{C}$. Meanwhile, the content of lignin decreased from 30 (untreated Poplar wood) to $14 \%$ in pulp obtained from CUB at $160{ }^{\circ} \mathrm{C}$ (i.e., a delignification extent of 53\%), and just $4 \%$ in pulp at $220{ }^{\circ} \mathrm{C}$ (delignification extent of $87 \%$ ). Likewise, the content of xylans decreased from $17 \%$ (untreated Poplar wood) to $14 \%$ in CUB pulps at $160{ }^{\circ} \mathrm{C}$, and then to $7 \%$ at $220^{\circ} \mathrm{C}$. On the consumption of $2-\mathrm{PrOH}$ as the $\mathrm{H}$-donor, it is not possible to decouple the effect of

Table 1. Comparison of weight yields of isolated fractions, pulp composition, and delignification extent obtained from organosolv and CUB processes under identical process conditions ${ }^{\mathrm{a}}$

\begin{tabular}{|c|c|c|c|c|c|c|c|c|}
\hline \multirow[t]{2}{*}{ Process type } & \multirow[t]{2}{*}{ Temperature $/{ }^{\circ} \mathrm{C}$} & \multicolumn{2}{|c|}{$\begin{array}{l}\text { Isolated fraction relative to } \\
\text { initial substrate weight / \% }\end{array}$} & \multicolumn{4}{|c|}{ Pulp composition b,c / wt. $\%$} & \multirow[t]{2}{*}{ Delignification / \% } \\
\hline & & Soluble & Pulp & Glucan & Xylan & Lignin & Others $^{\mathrm{d}}$ & \\
\hline Organosolv & 160 & 10 & 86 & 48 & 15 & 20 & 17 & 33 \\
\hline CUB & & 15 & 81 & 57 & 14 & 14 & 15 & 53 \\
\hline Organosolv & 180 & 30 & 70 & 79 & 11 & 7 & 3 & 77 \\
\hline CUB & & 25 & 71 & 66 & 11 & 11 & 12 & 63 \\
\hline Organosolv & 200 & 33 & 53 & 79 & 6 & 8 & 7 & 73 \\
\hline CUB & & 22 & 55 & 80 & 9 & 6 & 5 & 80 \\
\hline Organosolv & 220 & 36 & 46 & 81 & 3 & 7 & 9 & 77 \\
\hline CUB & & 26 & 52 & 84 & 7 & 4 & 5 & 87 \\
\hline
\end{tabular}

${ }^{\mathrm{a}}$ General experimental conditions: $16.5 \mathrm{~g}$ Poplar wood, $140 \mathrm{~mL}$ solvent (2-propanol:water, 7:3 v/v), $3 \mathrm{~h}$. CUB (catalytic upstream biorefining) experiments were performed with the addition of $10 \mathrm{~g}$ Raney $\mathrm{Ni}$ (wet); ${ }^{\mathrm{b}}$ obtained from analytical saccharification with sulfuric acid; ' unprocessed Poplar wood composition: glucans $52 \mathrm{wt} . \%$, xylans $17 \mathrm{wt} . \%$, lignin $30 \mathrm{wt} . \%$, others $1 \mathrm{wt} . \%$ (dry and ash-free values); din the pulps, as part of the unidentified other products, acid-soluble lignin and extractives can each comprise up to $2 \mathrm{wt} . \%$, respectively. 
an increase in soluble lignin fragments and hemicellulose sugars in the liquor from the effect of an increase in the extent of HDO with the process temperature. Therefore, to further examine the quantity of $\mathrm{H}$ transferred from 2-PrOH to the lignin species soluble in the liquor, we also carried out elemental analysis on the lignin streams, isolated by solvent removal under reduced pressure. Figure 2 compares the $\mathrm{O} / \mathrm{C}$ and $\mathrm{H} / \mathrm{C}$ molar ratios found in the isolated CUB lignin oils and organosolv lignins.

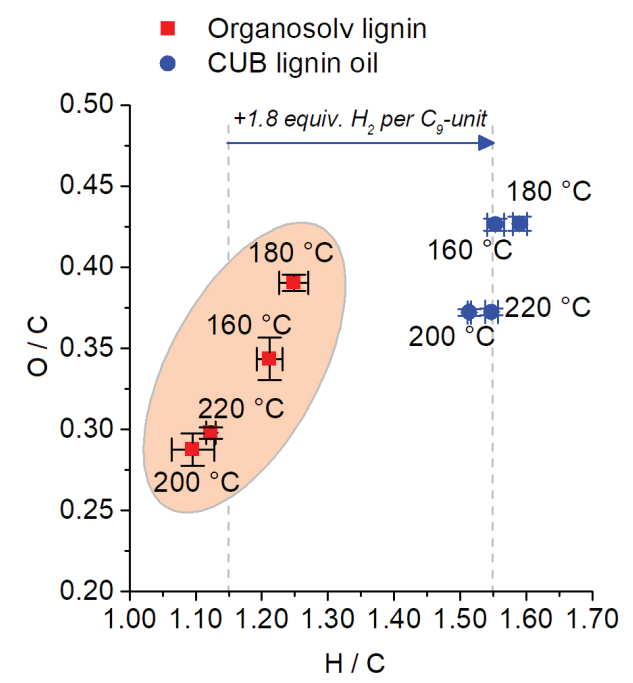

Figure 2. $\mathrm{O} / \mathrm{C}$ and $\mathrm{H} / \mathrm{C}$ mole ratios found in the isolated CUB lignin oils and organosolv lignins obtained at different process temperatures. Shaded area indicates values of organosolv lignin commonly reported in the literature. ${ }^{30-36}$

Figure 2 shows that organosolv lignins present average $\mathrm{O} / \mathrm{C}$ and $\mathrm{H} / \mathrm{C}$ mole ratios of 0.32 and 1.15 , respectively. Native Poplar lignins present a monomer composition of hydroxyphenyl- $(\mathrm{H})$, guaiacyl- $(\mathrm{G})$ and syringyl- $(\mathrm{S})$ units of $0.3: 38: 62 .{ }^{37}$ Therefore, for a hypothetical $\beta$-O-4-linked lignin structure containing a hundred repeating units at an $\mathrm{S} / \mathrm{G}$ ratio of 62:38, the simulated $\mathrm{O} / \mathrm{C}$ and $\mathrm{H} / \mathrm{C}$ mole ratios are 0.44 and 1.25 , respectively. The experimental values agree well with the simulated $\mathrm{O} / \mathrm{C}$ and $\mathrm{H} / \mathrm{C}$ mole ratios. Furthermore, the current values are also comparable to those already reported for organosolv lignins from hardwoods under varying conditions, as indicated by the orange shaded area (Figure 2)..$^{30,31,33-35}$ Regarding the CUB lignin oils, they exhibit an average $\mathrm{H} / \mathrm{C}$ mole ratio (1.5-1.6) markedly higher than that of the organosolv lignin counterparts, whereas an average $\mathrm{O} / \mathrm{C}$ mole ratio of 0.40 , which is close to those found for the organosolv counterparts. Assuming the CUB lignin oils to be a hypothetical mixture of S- and G-dihydro$p$-lignols at an $\mathrm{S} / \mathrm{G}$ ratio of $62: 38$, the current $\mathrm{O} / \mathrm{C}$ and $\mathrm{H} / \mathrm{C}$ mole ratio values found for the lignin oils are also comparable to the simulated values $(\mathrm{O} / \mathrm{C}$ and $\mathrm{H} / \mathrm{C}$ values of 0.34 and 1.43 , respectively).
Despite the very good agreement between experimental and simulated $\mathrm{H} / \mathrm{C}$ and $\mathrm{O} / \mathrm{C}$ ratios, the experimental values should be taken with caution as the lignin oils also contain in their composition approximately 5-10\% polyols, derived from the hydrogenation and hydrogenolysis of hemicellulose sugars, in addition to at least $30 \%$ of lignin oligomers and polymers. Likewise, organosolv lignin also carries over hemicellulose impurities. Nonetheless, in spite of the outlined limitations, the average $\Delta(\mathrm{H} / \mathrm{C})$ between organosolv lignins and CUB oils of $0.4 \mathrm{H} / \mathrm{C}$ suggests the addition of approximately 1.8 equivalent $\mathrm{H}_{2}$ per $\mathrm{C}_{9}$-propylphenyl unit of lignin in the lignin oil.

\section{Effect of temperature on the polymeric fraction of the lignin streams}

A key parameter in the evaluation of lignin streams is the apparent molar mass $\left(\mathrm{M}_{\mathrm{w}}\right)$ distributions, assessed by GPC. To examine the effect of temperature on CUB lignin oil streams, GPC analyses of the CUB lignin oils and organosolv lignins were performed. Figure 3 compares the GPC obtained for the lignin streams.

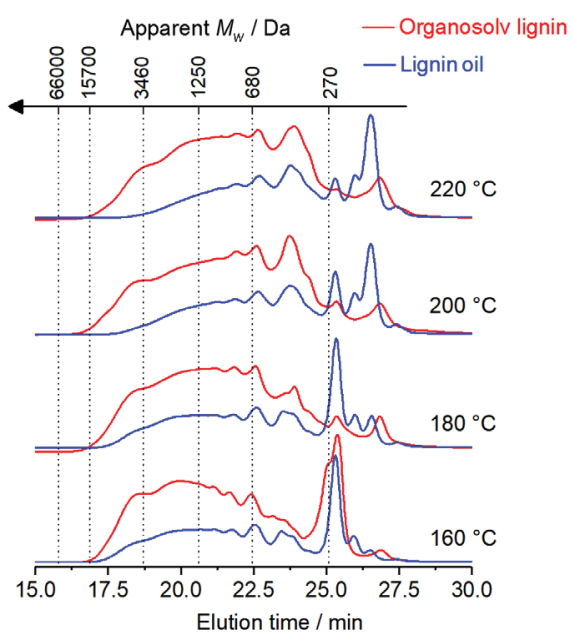

Figure 3. GPC of lignin products obtained from organosolv process (red line) and CUB (blue line) at various temperatures. Apparent molar mass $\left(\mathrm{M}_{\mathrm{w}}\right)$ is given relative to polystyrene standards. Chromatograms were normalized by sample concentration.

In Figure 3, organosolv lignin samples showed apparent $\mathrm{M}_{\mathrm{w}}$ distributions in the range of 100-20,000 Da. Increasing reaction temperature reduced the intensity of the signal at around 10,000 Da, while signal intensity at $400 \mathrm{Da}$ increased. As expected, in the organosolv process performed at temperatures of $200-220^{\circ} \mathrm{C}$, an increased extent of lignin depolymerization was obtained, owing to solvolytic processes on weak $\beta$-O-4 linkages. ${ }^{3}$ However, the observation of an intense peak centered at $250 \mathrm{Da}$ in the GPC of the organosolv lignin carried out at $160^{\circ} \mathrm{C}$ suggests 
that, at temperatures around $160^{\circ} \mathrm{C}$, the recondensation of lignin fragments might be kinetically not as pronounced as at the higher process temperatures.

The GPC of the CUB lignin oils showed in all cases much lower intensity for the species eluting between 16 and 23 min (apparent $\mathrm{M}_{\mathrm{w}}$ between $15 \mathrm{kDa}$ and $600 \mathrm{Da}$, respectively, Figure 3). Additionally, the results indicate that higher temperatures favor the formation of species of $\mathrm{M}_{\mathrm{w}}$ lower than $600 \mathrm{Da}$. The chromatograms show that the addition of the catalyst is necessary to obtain low $\mathrm{M}_{\mathrm{w}}$ discreet molecules (ca. 100-200 Da). Overall, the increased depolymerization is due to the catalytic activity of Raney $\mathrm{Ni}$ for the cleavage of aryl alkyl ether bonds. ${ }^{20}$

Although it seems logical that the reductive processes on extracted lignin species will quench their reactivity toward recondensation via electrophilic aromatic substitution and other $\mathrm{C}-\mathrm{C}$ forming reactions, there is still no direct evidence presented in the current literature demonstrating that recondensation is indeed suppressed. To shed light on the prevention of recondensation reactions via reductive processes, we examined the UV-Vis spectra of the eluting species during GPC analysis (Figure 4). Compared to the organosolv lignin species, the species produced in the
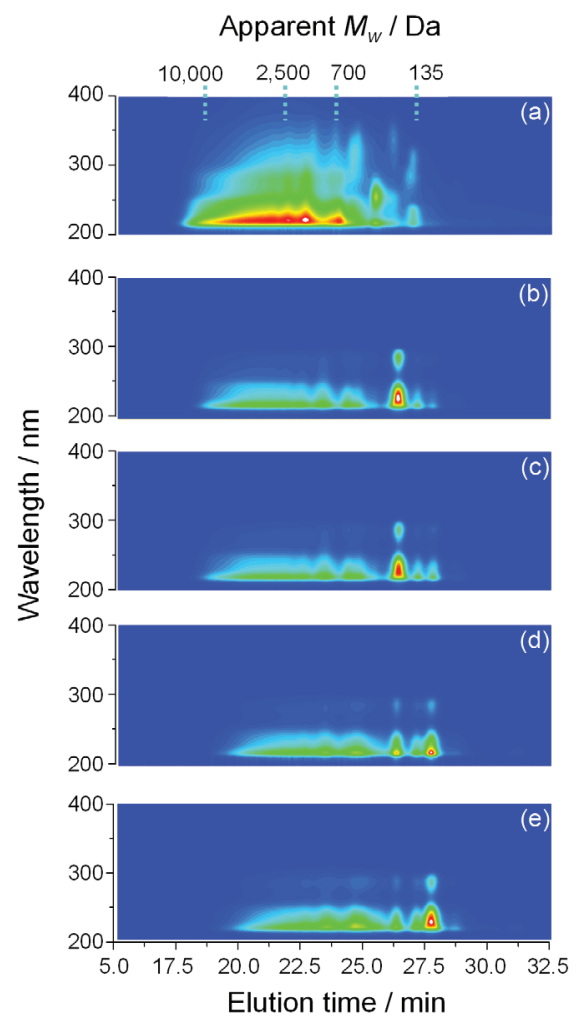

Figure 4. UV-Vis spectra of lignin products (produced in $2-\mathrm{PrOH} / \mathrm{H}_{2} \mathrm{O}$, $7: 3 \mathrm{v} / \mathrm{v}$ ) upon elution from GPC columns during analysis. (a) Organosolv lignin obtained at $180{ }^{\circ} \mathrm{C}$; (b) CUB lignin at process temperature $160^{\circ} \mathrm{C}$; (c) CUB lignin at process temperature $180^{\circ} \mathrm{C}$; (d) CUB lignin at process temperature $200{ }^{\circ} \mathrm{C}$; and (e) CUB lignin at process temperature $220^{\circ} \mathrm{C}$. Apparent $\mathrm{M}_{\mathrm{w}}$ is given relative to polystyrene standards.
CUB process do not show an intense absorbance response at wavelengths higher than $300 \mathrm{~nm}$. This observation is particularly revealing as it is known that some substituted phenolics, such as those of recondensed lignin, do indeed show a strong absorption at wavelengths $>300 \mathrm{~nm} .^{38}$ Therefore, the inspection of the UV-Vis spectra collected in GPC analysis provides initial evidence that recondensation is prevented by the reductive processes on the lignin fragments.

To learn more about the evolution of the connectivity of polymeric lignin substructures with the process temperature, two-dimensional HSQC NMR spectra of the lignin streams were collected. From the 2D NMR spectra, it is possible to estimate the abundance of $\beta-\mathrm{O}-4$ (A), phenylcoumarantype (B) and resinol-type (C) linkages, which are bonding motifs occurring in native lignins (Scheme 3 ). ${ }^{39}$ Figure 5 compares the 2D HSQC NMR spectra of the organosolv lignins and CUB lignin oils, in the region of the aryl-ether linkages $\mathbf{A}, \mathbf{B}$ and $\mathbf{C}$.

$$
\mathrm{R}:-\mathrm{H} \text { or }-\mathrm{OCH}_{3}
$$

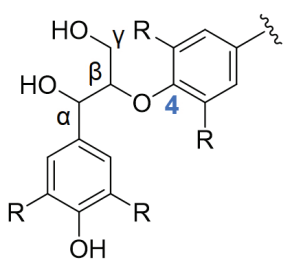

B-O-4

(A)

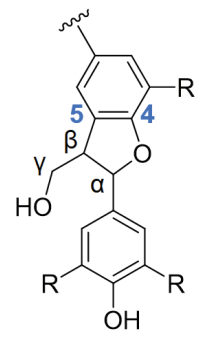

$\beta-5$

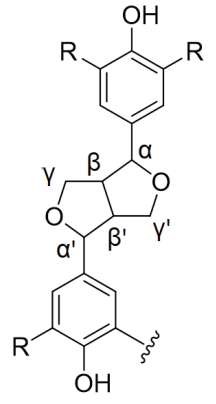

$\beta-\beta$
Scheme 3. Common lignin linkages (highlighted as $\mathbf{A}, \mathbf{B}$ and $\mathbf{C}$ in the HSQC NMR spectra, Figure 5).

2D HSQC NMR spectra revealed that signals assigned to the phenylcoumaran-type linkages, detected in the organosolv lignin spectra, were not present in the CUB lignin oils. The ratio of the intensity of $\mathrm{A} \alpha$ and $\mathrm{C} \alpha$ signals $(\mathrm{A} \alpha / \mathrm{C} \alpha)$ can be used as an indication of the conversion of the $\beta$-O-4 linkages compared to the resinol units. The influence of process temperature on this ratio can be observed in the spectra of organosolv lignin. For organosolv lignins obtained at $160,180,200$, and $220^{\circ} \mathrm{C}$, the ratio is $1.6,1.5,1.3$, and 1.3 , respectively. In stark contrast, for the CUB lignin oils' spectra, a greater decrease in the $\mathrm{A} \alpha / \mathrm{C} \alpha$ ratio was observed: $1.3\left(160^{\circ} \mathrm{C}\right), 1.1\left(180^{\circ} \mathrm{C}\right), 1.0\left(200^{\circ} \mathrm{C}\right)$ and $0.9\left(220^{\circ} \mathrm{C}\right)$. These observations, together with those collected from GPC analysis, demonstrate that Raney Ni is highly effective at both the passivation of the lignin fragments and the reductive depolymerization of lignin via $\mathrm{H}$-transfer hydrogenolysis of lignin's ether linkages. 


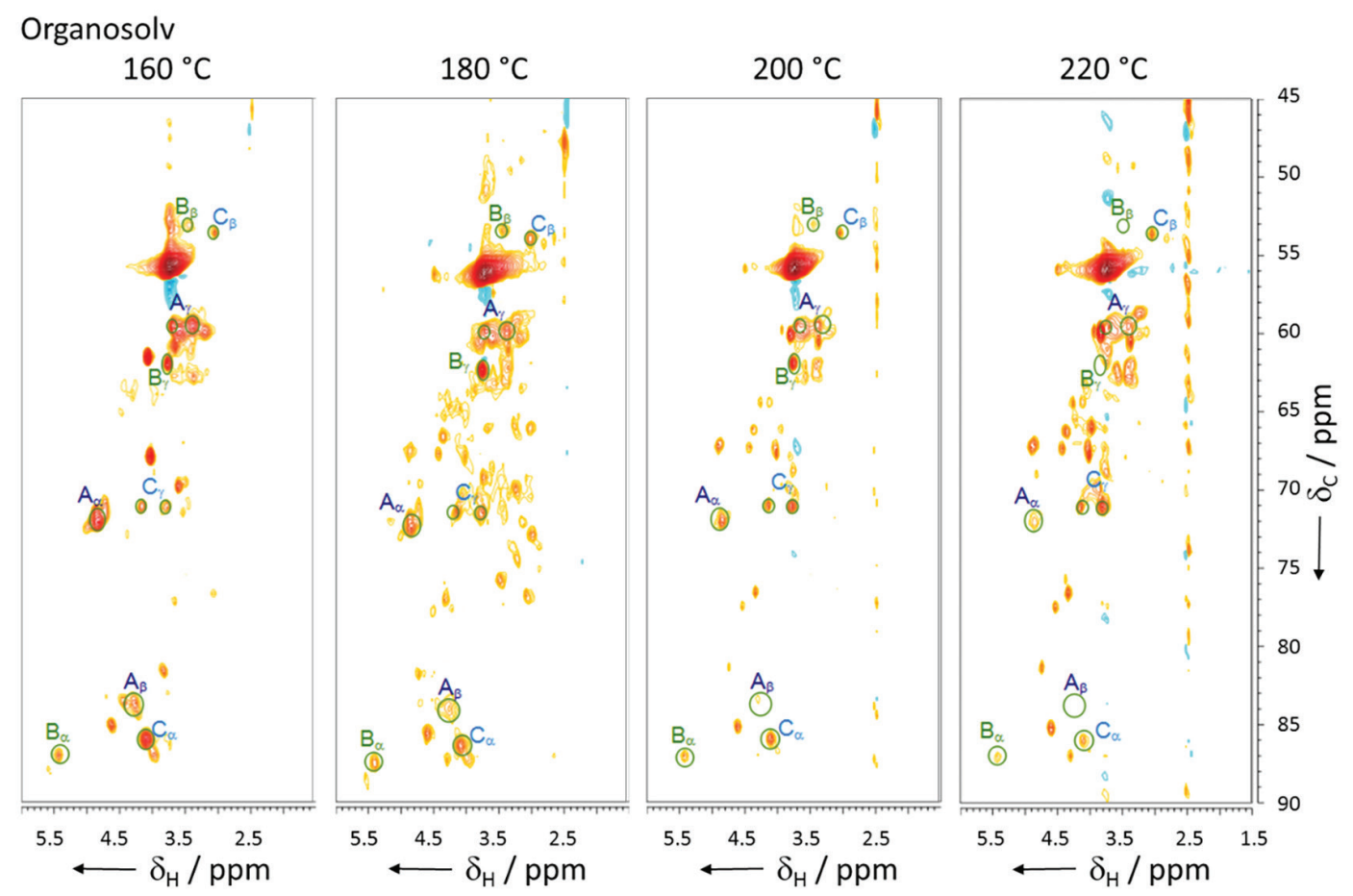

\section{Catalytic upstream biorefining}
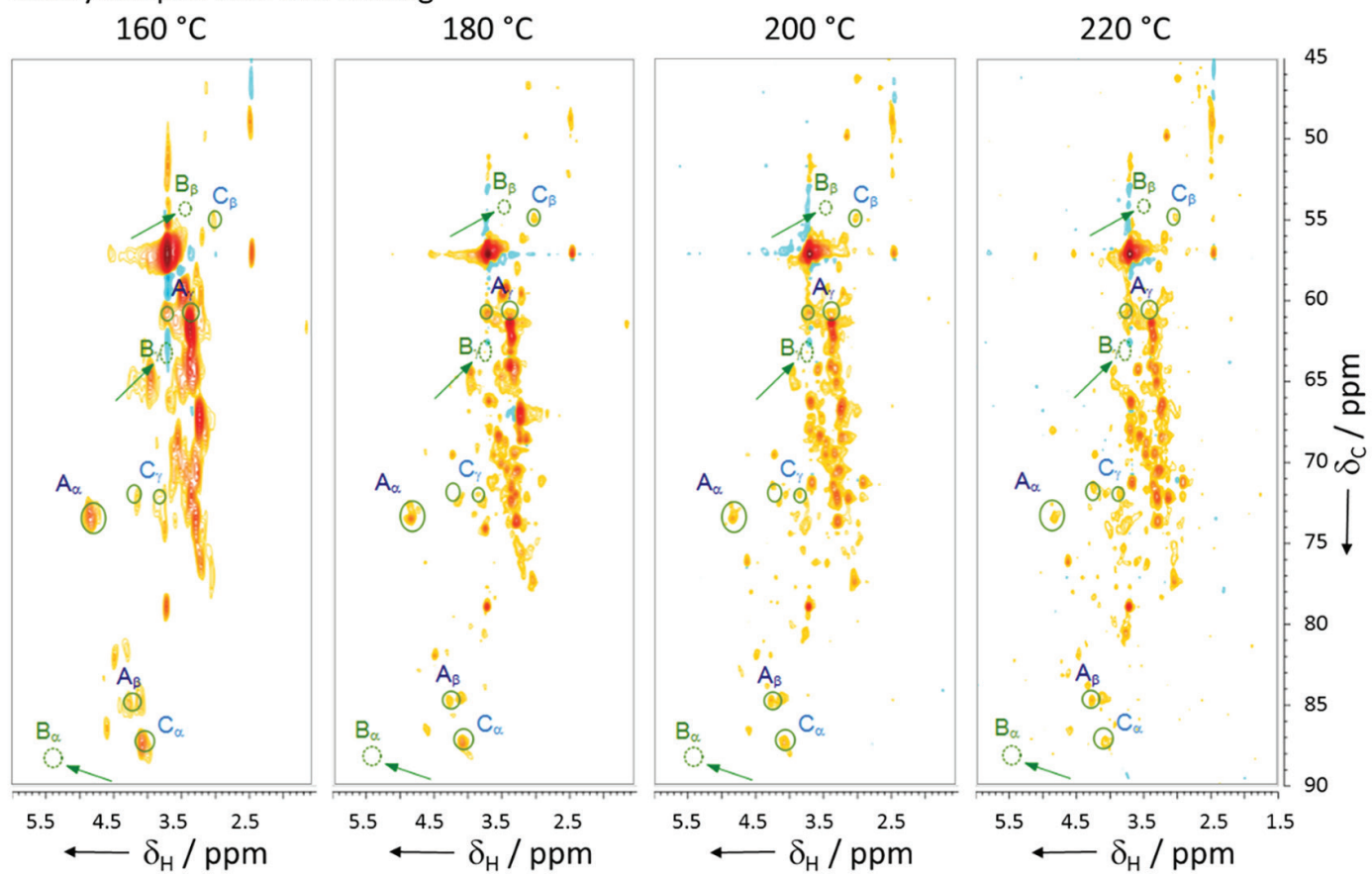

Figure 5. 2D HSQC NMR spectra of organosolv lignin (top) and lignin oil (bottom) obtained at various process temperatures. For the missing fingerprint signals in the lignin oil spectra, the regions are highlighted with arrows.

Impact of temperature on the distribution of low $\mathrm{M}_{\mathrm{w}}$ products in the lignin oils

The low $\mathrm{M}_{\mathrm{w}}$ fraction (up to approximately $300 \mathrm{Da}$ ) of the lignin products can be analyzed by GC. For the analysis of the CUB lignin oil samples, two-dimensional
$\mathrm{GC} \times \mathrm{GC}$ was employed as it allows better resolution and higher sensitivity in the mass spectrometry (MS)-based product identification, compared to the one-dimensional GC. To compare the compositions of the lignin oils, 17 compounds were selected and 2D GC $\times$ GC-FID images analyzed (Figures S1-S4, Supplementary Information 
(SI) section). Compounds were identified by comparison of their mass spectra with libraries (National Institute of Standards and Technology (NIST) 08, NIST 08s, and Wiley 9) or by comparison to authentic samples (electron ionization (EI)-MS for compounds $\mathbf{1 a}, \mathbf{1 b}$ and $\mathbf{1} \mathbf{c}$ are shown in Figure S5, SI section).

The selection of the compounds listed in Table 2 is justified as follows. Compounds 1-6 are the primary components of the CUB oils. They provide insight into the extent of HDO and cracking on the propyl side-chain of the lignin-derived phenolics. Moreover, if no demethoxylation takes place, the analog series described by a number followed by the letters $\mathbf{a}, \mathbf{b}$ or $\mathbf{c}$ should relate to the natural abundance of H-, G- and S-units, respectively. Native Poplar lignins present very low content of $\mathrm{H}$-units. Hence, they are often referred to as S / G-lignins. ${ }^{37}$

Table 2. The content of selected lignin products of CUB performed at the indicated temperatures, as determined by GC $\times$ GC-FID

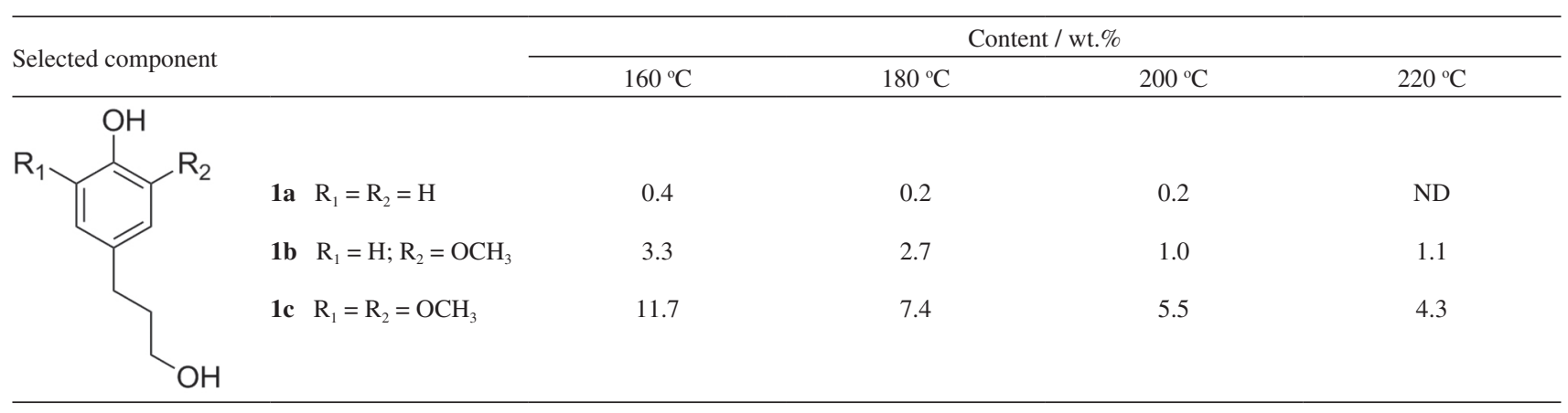

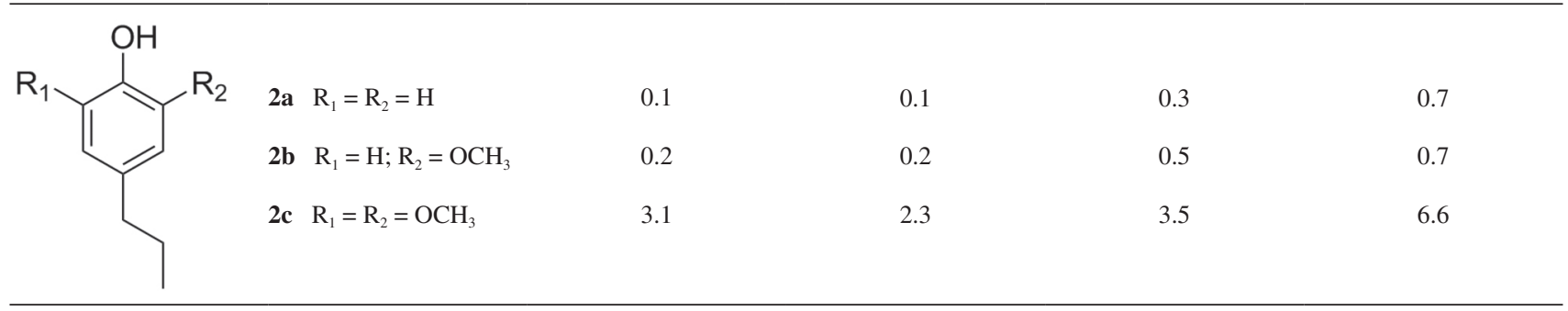<smiles>[R]c1cc(CC)cc([R])c1O</smiles>

\begin{tabular}{|c|c|c|c|c|}
\hline 3a $\quad \mathrm{R}_{1}=\mathrm{R}_{2}=\mathrm{H}$ & 0.2 & 0.3 & 0.5 & 1.9 \\
\hline 3b $\mathrm{R}_{1}=\mathrm{H} ; \mathrm{R}_{2}=\mathrm{OCH}_{3}$ & 0.4 & 0.7 & 2.5 & 3.9 \\
\hline 3c $\mathrm{R}_{1}=\mathrm{R}_{2}=\mathrm{OCH}_{3}$ & 1.3 & 2.2 & 5.4 & 10.3 \\
\hline
\end{tabular}

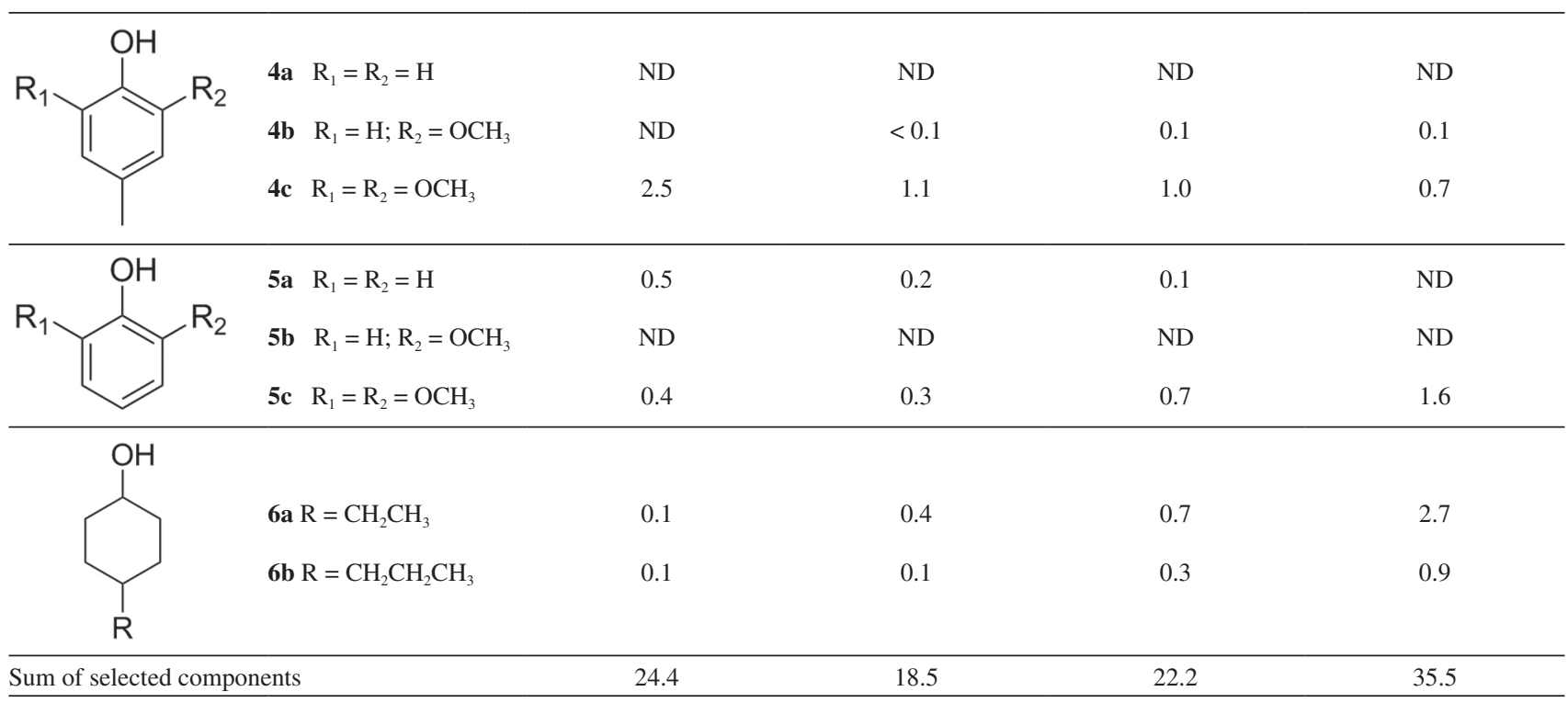

ND: not detected. The relative standard deviation (RSD) was lower than $5 \%$ in all cases. 
The data from Table 2 also indicated that the conversion of compounds $\mathbf{1 a}, \mathbf{1 b}$ and $\mathbf{1 c}$ into $\mathbf{2 / 3 a}, \mathbf{2 / 3 b}$ and $\mathbf{2 / 3 c}$ is a key reaction in the consumption of 4-(3-hydroxypropyl)phenols (Scheme 4). Indeed, the content of 4-(3-hydroxypropyl) phenols (1) decreases significantly when the process temperature is raised from 160 to $220{ }^{\circ} \mathrm{C}$. In particular, 1b decreases from 3.3 to $1.1 \mathrm{wt} \%$, and $\mathbf{1 c}$ from 11.7 to $4.3 \mathrm{wt}$.\%. At the same time, an increase in compounds $\mathbf{2 b}$ (0.2 to 0.7$), \mathbf{2 c}$ (3.1 to 6.6$), \mathbf{3 b}(0.4$ to 3.9$)$ and $\mathbf{3 c}$ (1.3 to 10.3 wt. \%) is observed. Compounds $\mathbf{2 a - 2 \mathbf { c }}$ derive from the loss of hydroxyl group in the side chain of $\mathbf{1}$, while $\mathbf{3}$ can be the product of the cleavage of the $\mathrm{C}_{\beta}-\mathrm{C}_{\gamma}$ bond of the 4-(3-hydroxypropyl)phenols (1), resulting in the release of formaldehyde. ${ }^{40}$

Table 3 compares the mole ratio $\mathbf{1 a}: \mathbf{1 b}: \mathbf{1 c}$ with the expected monomer composition and reveals information on the extent of demethoxylation.

Table 3. H:G:S molar ratio in native Poplar lignin and in the lignin oils obtained by CUB, as determined by the mole ratio of compounds 1a:1b:1c in Table 2

\begin{tabular}{lccc}
\hline & $\mathrm{H}$ & $\mathrm{G}$ & $\mathrm{S}$ \\
\hline Native Poplar lignin $^{37}$ & 0.3 & 38 & 62 \\
\hline Lignin oil, $160^{\circ} \mathrm{C}$ & 4 & 24 & 72 \\
Lignin oil, $180^{\circ} \mathrm{C}$ & 3 & 29 & 68 \\
Lignin oil, $200^{\circ} \mathrm{C}$ & 5 & 16 & 79 \\
Lignin oil, $220^{\circ} \mathrm{C}$ & 0 & 23 & 77 \\
\hline
\end{tabular}

H: hydroxyphenyl; G: guaiacyl; S: syringyl.

Interestingly, the relative contents of $\mathbf{1 a}$ and $\mathbf{1 c}$ were higher than those expected from the content of $\mathrm{H}$ - and $\mathrm{S}$-units commonly found in native Poplar lignins, while the relative content of $\mathbf{1 b}$ was lower than that expected from the content of G-units (Table 3). This result suggests that $\mathbf{1 b}$ shows a higher reactivity towards demethoxylation, generating 1a (Scheme 5). Notably, although 1c could also undergo demethoxylation to give $\mathbf{1 b}$, this transformation seems to be less important in the CUB process. Consequently, the

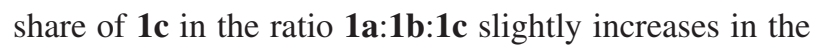
lignin oil obtained from the processes carried out at higher temperatures $\left(200\right.$ and $\left.220^{\circ} \mathrm{C}\right)$.

Furthermore, between 160 and $220{ }^{\circ} \mathrm{C}$, the increase of production of $\mathbf{3}$ from HDO of $\mathbf{1}$ is higher than the hydrogenation of the aromatic ring to form $\mathbf{6}$, even at high temperature, suggesting that HDO reactions of lignin fragments are more pronounced than the hydrogenation of the aromatic rings. Raising the temperature from 200 to $220{ }^{\circ} \mathrm{C}$ favors the hydrogenation of the aromatic ring, as suggested by the sudden increase of $\mathbf{6 a}$ and $\mathbf{6 b}$. The compounds selected in Table 2 constituted between 18.5 and $35.5 \mathrm{wt} . \%$ of the total CUB products, corroborating the GPC data (Figure 3) that indicated a significant fraction of the product oil was composed of lignin monomers.

In contrast to pyrolysis oils, which contain several reactive aromatic ketones and aldehydes, the $2 \mathrm{D} G \mathrm{GC} \times \mathrm{GC}$ analysis showed that these compounds are not present in the oil mixture. Therefore, it was expected that CUB lignin oil could be fractionated by short-path (Kugelrohr) distillation under reduced pressure (1 mbar). Such fractionation is not possible to be performed on pyrolysis oils due to their high intrinsic reactivity towards repolymerization, forming chars upon heating. To reaffirm that CUB lignin oils are formed by stable phenolics, which are indeed discreet volatiles, a short-path distillation of a CUB lignin oil (obtained under optimized conditions) was performed (results are outlined in Figure 6). The fractions removed at various temperature intervals were characterized using $2 \mathrm{D} \mathrm{GC} \times \mathrm{GC}-\mathrm{MS}$ (Figures S6-S12, SI section). Initially, at temperatures ranging from $100-130{ }^{\circ} \mathrm{C}$ diols, such as 1,2 -propanediol

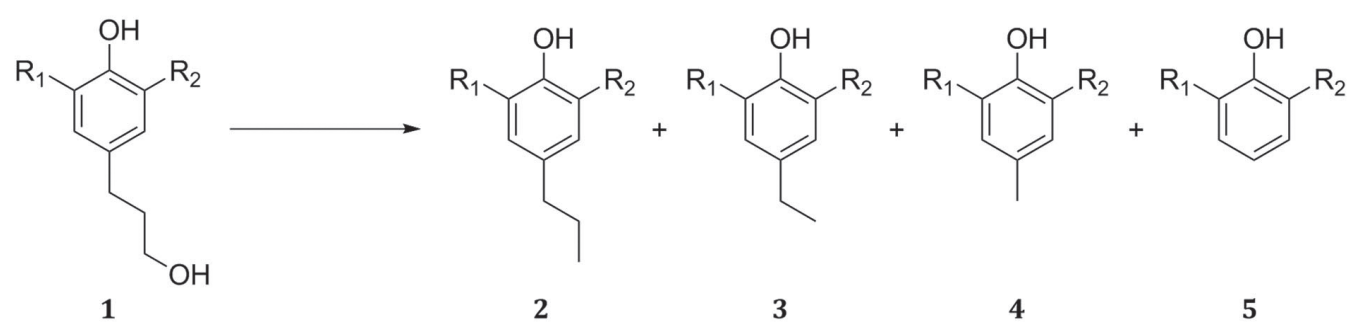

Scheme 4. Reaction channel leading to deoxygenation and shortening of the side chain of $\mathbf{1}$.

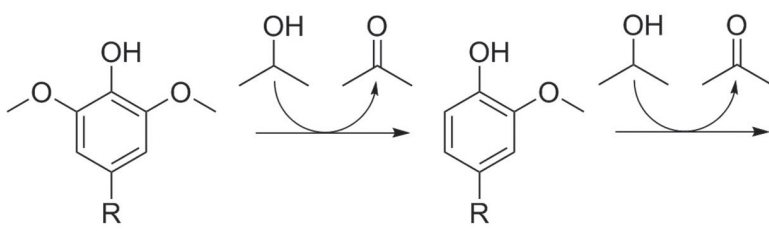<smiles>[R]c1ccc(O)cc1</smiles><smiles>[R]C1CCC(O)C(CC(C)C(=O)CC(C)(C)O)C1</smiles>

Scheme 5. Reaction channel for HDO through demethoxylation and hydrogenation. 


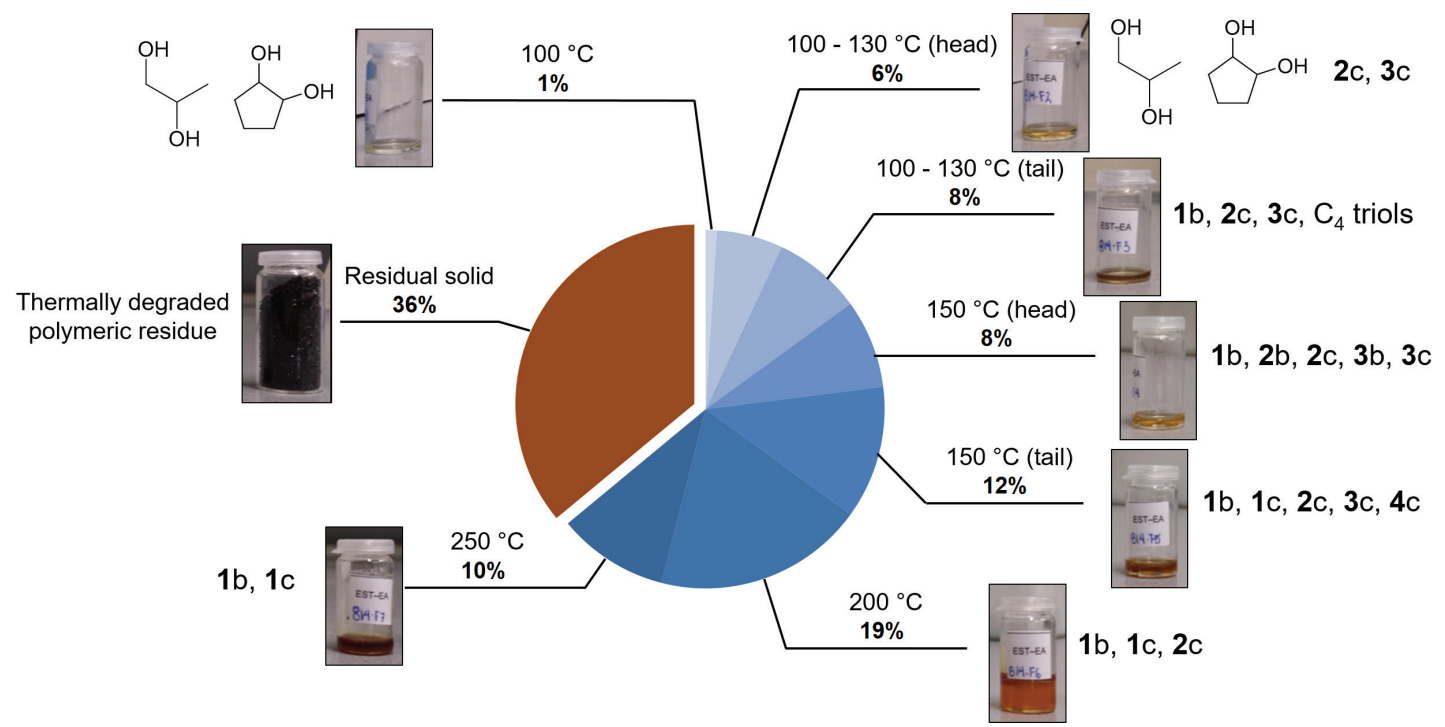

Figure 6. Fractionation of a CUB lignin oil by short-path (Kugelrohr) distillation under reduced pressure (1 mbar); temperature of each fraction is displayed along with the total yield (wt.\%) of each fraction. Photographs of each fraction are coupled with the typical compounds distilled at each temperature (as determined by GC $\times$ GC-MS).

and 1,2-cyclopentanediol, were predominantly detected. At the tail end of the $100-130{ }^{\circ} \mathrm{C}$ range, the removal of lignin products $\mathbf{1 b}, \mathbf{2 c}$ and $\mathbf{3 c}$, outlined in Table 2, became more pronounced. Increasing the temperature to $150-250{ }^{\circ} \mathrm{C}$, more of these lignin products were obtained, with temperatures predominantly yielding compounds $\mathbf{1 b}$ and $\mathbf{1 c}$, with some $\mathbf{2 c}, \mathbf{3 c}$ and $\mathbf{4 c}$ also present. Noteworthy, the combination of fractions collected between 150 and $250{ }^{\circ} \mathrm{C}$ totalized 49 wt.\% of the CUB lignin oil. Above temperatures of $250{ }^{\circ} \mathrm{C}$, only solid thermally degraded polymeric residue remained, which accounted for $36 \mathrm{wt} . \%$ of the lignin oil.

\section{Conclusions}

The effect of temperature on both CUB process and an organosolv lignin process on Poplar wood was investigated. CUB experiments carried out in the presence of Raney Ni hydrogenation catalyst display improved catalyst activity at higher temperatures, favoring transfer hydrogenation and hydrogenolysis of the aromatic polymer. It was demonstrated that process temperature is a crucial parameter to tune the composition of these CUB lignin oil product mixtures, including by significantly improving overall extraction yields (up to 87\%) and the production of discreet low $\mathrm{M}_{\mathrm{w}}$ molecules by increased cleavage of $\beta$-O-4 linkages, confirmed using 2D HSQC NMR spectroscopy, and passivation of reactive lignin fragments via hydrogenation, as demonstrated by the $2 \mathrm{D}$ GC $\times$ GC results. GPC confirmed the production of more low $\mathrm{M}_{\mathrm{w}}$ material in high-temperature CUB processes with the emergence of higher intensity peaks at longer elution times. Conversely, increasing temperatures in the production of organosolv lignins appear to promote recondensation, with peak intensities at higher elution times decreasing with the process temperature. Increasing the temperature to above $200{ }^{\circ} \mathrm{C}$ favored the degradation of the propyl side-chain of the dihydro- $p$-lignol species (1). Surprisingly, a facile reaction in the presence of Raney $\mathrm{Ni}$ under H-transfer conditions, ${ }^{20}$ the demethoxylation of lignin phenols, was inhibited under the CUB conditions. Finally, owing to the increased stability imparted by the passivation process, a CUB oil was fractionated via distillation, confirming that the lignin oils were comprised of primarily discreet aromatics and low $\mathrm{M}_{\mathrm{w}}$ compounds, with only $36 \%$ of the lignin occurring as a thermally degraded polymeric residue.

\section{Experimental}

Materials

Raney Ni 2800 slurry, 2-propanol (99.9\%), ethyl acetate (99\%), tetrahydrofuran (THF; 99.9\%), dibutyl ether $(99 \%)$ and deuterated dimethyl sulfoxide (DMSO- $d_{6}$ ) were purchased from Sigma-Aldrich and used as received. Poplar wood ( $2 \mathrm{~mm}$ pellets) was supplied by J. Rettenmaier \& Söhne and were used as received.

\section{Catalytic upstream biorefining process with Raney $\mathrm{Ni}$}

Poplar wood (16-17 g) and Raney Ni (10 g wet) in a solution of 2-PrOH:water $(140 \mathrm{~mL}, 7: 3 \mathrm{v} / \mathrm{v})$ were placed in a $250 \mathrm{~mL}$ autoclave and heated to the desired temperature 
$\left(160-220{ }^{\circ} \mathrm{C}\right)$ within $1 \mathrm{~h}$ under mechanical stirring. The reaction proceeded under autogenous pressure for $3 \mathrm{~h}$. In sequence, the mixture was left to cool down to room temperature. The liquor was separated from the solids (Raney Ni plus pulp) by filtration through a glass fiber filter (GF6, Ø $90 \mathrm{~mm}$, Whatman). The wet solids were immediately poured into a round-bottom flask $(250 \mathrm{~mL})$ containing 2-PrOH. Under overhead mechanical stirring, the solids were resuspended in 2-PrOH. Raney Ni was attracted to the flask bottom by a magnet externally placed on the bottom of the round flask. This procedure was repeated until the catalyst was removed entirely from the pulp fibers (5-6 times). The pulp fibers remained in suspension and were recovered by filtration. The liquor and the filtrates (from the catalyst separation procedure) were combined. The lignin oil was isolated by removing the solvent at $60^{\circ} \mathrm{C}$ under vacuum with a rotary evaporator.

\section{Organosolv process}

Poplar wood (16-17 g) was suspended in a solution of 2-PrOH:water ( $140 \mathrm{~mL}, 7: 3 \mathrm{v} / \mathrm{v})$ in a $250 \mathrm{~mL}$ autoclave and heated to the desired temperature $\left(160-220^{\circ} \mathrm{C}\right)$ within $1 \mathrm{~h}$ under mechanical stirring. The suspension was processed under autogenous pressure for $3 \mathrm{~h}$. In sequence, the mixture was left to cool down to room temperature. A reddish-brown solution (liquor) was obtained after filtering out the pulp fibers. The pulp was washed several times with 2-propanol portions $(20 \mathrm{~mL})$ and then dried under vacuum. Organosolv lignin (containing hemicellulose impurities) was isolated from the liquor by removing the solvent mixture at $60{ }^{\circ} \mathrm{C}$ under vacuum using a rotary evaporator. Organosolv lignin was obtained as a reddish-brown solid residue.

\section{Product characterization}

The amount of acetone produced in the CUB was determined by GC-FID analysis. For the analysis, $100 \mu \mathrm{L}$ of liquor was filtered (nylon filters, $0.45 \mu \mathrm{m}$ ) and diluted in $1 \mathrm{~mL}$ ethyl acetate. Di- $n$-butyl ether $(5 \mathrm{mg}$ ) was added as standard to the solution and the samples were analyzed in a GC-FID 2010 Plus (Shimadzu), using Zebron ZB-1HT Inferno column ( $30 \mathrm{~m}, 0.25 \mathrm{~mm}$ i.d., d.f. $0.25 \mu \mathrm{m})$. To allow separation of acetone from 2-PrOH, the temperature program started with an isotherm at $28{ }^{\circ} \mathrm{C}$ for $3 \mathrm{~min}$. Afterwards, the column temperature was raised first to $35^{\circ} \mathrm{C}\left(\right.$ rate of $\left.1{ }^{\circ} \mathrm{C} \mathrm{min}-1\right)$, then to $300^{\circ} \mathrm{C}\left(\right.$ rate of $\left.50^{\circ} \mathrm{C} \mathrm{min}^{-1}\right)$ and it was held at $300{ }^{\circ} \mathrm{C}$ for $5 \mathrm{~min}$.

Elemental analysis was performed with an Elementar VarioMICRO Cube, on 3-4 mg of organosolv lignin or CUB lignin oil, to determine the $\mathrm{C} / \mathrm{H} / \mathrm{N}$ content. The operating temperatures for the combustion and reduction tubes were 1150 and $850{ }^{\circ} \mathrm{C}$, respectively. Oxygen flow was kept for $80 \mathrm{~s}$. Each analysis was repeated at least three times. The oxygen content in the sample was determined by subtraction.

To obtain apparent molar mass distribution of lignin products, the samples (10 to $30 \mathrm{mg}$ ) were dissolved in THF $(2 \mathrm{~mL})$ and filtered (nylon filter, $0.45 \mu \mathrm{m})$ prior to injection. The GPC analyses were performed at $60^{\circ} \mathrm{C}$ on a PerkinElmer high performance liquid chromatograph (HPLC) 200 equipped with four columns (2 TSKgel Super HZ1000, TSKgel Super HZ2000 and TSKgel Super HZ3000, $4.6 \mathrm{~mm} \times$ i.d. $15.0 \mathrm{~cm}$, Tosoh Bioscience), and using inhibitor-free THF as eluent $\left(0.4 \mathrm{~mL} \mathrm{~min}^{-1}\right.$, Aldrich). For detection, a diode-array detector (DAD) and an evaporative light scattering detector (ELSD) were used. The results reported for the DAD show the chromatogram at $216 \mathrm{~nm}$. The detector's response was normalized by the sample weight. The apparent molar mass is given relative to polystyrene standards (200 to 60,000 Da, Aldrich).

$\mathrm{GC} \times \mathrm{GC}$ analysis was performed on filtered samples (nylon filters, $0.45 \mu \mathrm{m}$ ) by using a GC-MS 2010 Plus (Shimadzu) equipped with a ZX1 thermal modulation system (Zoex). Typically, the separation in the first dimension was performed by a nonpolar column (for Figures S1-S4 (SI section): Rxi-1ms 30 m, 0.25 mm i.d., d.f. $0.25 \mu \mathrm{m}$ or, for Figures S6-S12 (SI section): Zebron ZB-1HT Inferno $30 \mathrm{~m}, 0.32 \mathrm{~mm}$ i.d., d.f. $0.25 \mu \mathrm{m}$ ); the separation in the second dimension was carried out by a mid-polarity column (for Figures S1-S4 (SI section): BPX50, 1 m, 0.15 mm i.d., d.f. $0.15 \mu \mathrm{m}$, or Figures S6-S12 (SI section): BPX50, $0.8 \mathrm{~m}, 0.15 \mathrm{~mm}$ i.d., d.f. $0.15 \mu \mathrm{m}$ ). The injector temperature was $300^{\circ} \mathrm{C}$. The temperature program started with an isothermal step at $40^{\circ} \mathrm{C}$ for $5 \mathrm{~min}$. Next, the temperature was increased from 40 to $300^{\circ} \mathrm{C}$ by $5.2^{\circ} \mathrm{C} \mathrm{min}^{-1}$. The program finished with an isothermal step at $300^{\circ} \mathrm{C}$ for $5 \mathrm{~min}$. The modulation applied for the comprehensive GC $\times \mathrm{GC}$ analysis was a hot jet pulse (400 ms) every $9000 \mathrm{~ms}$. The 2D chromatograms were reconstructed with GC Image software (Zoex). The products were identified by comparing the MS spectrum with libraries: NIST 08, NIST 08s, and Wiley 9. In some cases, the structure was proposed by the analysis of the EI-fragmentation pattern and by comparison of retention times with authentic samples, or by comparison with reported spectra. ${ }^{41} \mathrm{GC} \times \mathrm{GC}$-FID images were used for the determination of the selected species' contents. When analytical standards were not available, the FID response factor was estimated by using effective carbon number (ECN) concept. ${ }^{42}$

All HSQC NMR spectra were acquired at $25{ }^{\circ} \mathrm{C}$ in DMSO- $d_{6}$ with a Bruker AV spectrometer $(400$ or $500 \mathrm{MHz}$ 
${ }^{1} \mathrm{H}$ frequency) equipped with a BBFO probe head with $z$-gradient. The 2D HSQC NMR (Bruker standard pulse sequence "hsqcetgpsi" with delay optimized for ${ }^{1} J_{\mathrm{CH}}$ of $145 \mathrm{~Hz}$ ) was set up with spectral widths of 20 and $180 \mathrm{ppm}$ for ${ }^{1} \mathrm{H}$ - and ${ }^{13} \mathrm{C}$-dimensions, respectively. The number of collected complex points was 2,048 for ${ }^{1} \mathrm{H}$-dimension with a recycle delay of $3.13 \mathrm{~s}$ ( $3.0 \mathrm{~s}$ relaxation delay and $0.13 \mathrm{~s}$ acquisition time). The number of transients for the HSQC spectra was between 12 and 24, and 512-time increments were recorded in ${ }^{13} \mathrm{C}$-dimension, resulting in an overall experiment time of 6 to $12 \mathrm{~h}$. For HSQC experiments, a squared cosine-bell apodization function was applied in both dimensions, followed by zero-filling to 1,024 points in the ${ }^{13} \mathrm{C}$-dimension prior to Fourier transform. All 2D HSQC NMR spectra were processed using MestReNova 8.1.1 software. ${ }^{43}$ Worth noting HSQC spectrum data must be interpreted with caution since the ${ }^{1} J_{\mathrm{CH}}$ dependence of polarization transfer in HSQC experiments is not suppressed in regular HSQC pulse sequences..$^{44}$ As a result, the absolute intensities of cross peaks are not fully quantitative in the entire spectral range. ${ }^{41,44-46}$ Semiquantitative determination of volume integral ratios is possible for ${ }^{1} \mathrm{H}-{ }^{13} \mathrm{C}$ pairs in a similar chemical environment (e.g., $\mathrm{C}_{\alpha}-\mathrm{H}_{\alpha}$ signals for the side-chain of lignin units), because the ${ }^{1} J_{\mathrm{CH}}$ values for the specific entities are reasonably similar. ${ }^{37}$ Accordingly, for the different regions of the HSQC spectra, the semiquantitative analysis was performed separately by integration of ${ }^{1} \mathrm{H}-{ }^{13} \mathrm{C}$ pairs of interest.

\section{Supplementary Information}

Supplementary information $(\mathrm{GC} \times \mathrm{GC}$ chromatograms of lignin oil produced at various process temperatures and of lignin oil fractions collected from Kugelrohr distillation) is available free of charge at http://jbcs.sbq.org.br as PDF file.

\section{Acknowledgments}

R. R. and R. W. are grateful to the financial support provided by the ERC Consolidator Grant LIGNINFIRST (project number: 725762).

\section{References}

1. Ferrini, P.; Rinaldi, R.; Angew. Chem., Int. Ed. 2014, 53, 8634.

2. Renders, T.; Van den Bosch, S.; Koelewijn, S.-F.; Schutyser, W.; Sels, B.; Energy Environ. Sci. 2017, 10, 1551.

3. Rinaldi, R.; Jastrzebski, R.; Clough, M. T.; Ralph, J.; Kennema, M.; Bruijnincx, P. C. A.; Weckhuysen, B. M.; Angew. Chem., Int. Ed. 2016, 55, 8164.
4. Schutyser, W.; Renders, T.; Van den Bosch, S.; Koelewijn, S.-F.; Beckham, G. T.; Sels, B. F.; Chem. Soc. Rev. 2018, 47, 852.

5. Rinaldi, R.; Schüth, F.; ChemSusChem 2009, 2, 1096.

6. Davoudzadeh, F.; Smith, B.; Avni, E.; Coughlin, R. W.; Holzforschung 1985, 39, 159.

7. Vuori, A.; Bredenberg, J.-S.; Holzforschung 1988, 42, 155.

8. Fiege, H.; Voges, H.-V.; Hamamoto, T.; Umemura, S.; Iwata, T.; Miki, H.; Fujita, Y.; Buysch, H.-J.; Garbe, D.; Paulus, W. In Ullmann's Encyclopedia of Industrial Chemistry; Elvers, B., ed.; Wiley-VCH: Weinheim, 2000, p. 521.

9. Galkin, M. V.; Dahlstrand, C.; Samec, J. S.; ChemSusChem 2015, 8, 2187.

10. Galkin, M. V.; Samec, J. S.; ChemSusChem 2014, 7, 2154.

11. Van den Bosch, S.; Schutyser, W.; Vanholme, R.; Driessen, T.; Koelewijn, S.-F.; Renders, T.; De Meester, B.; Huijgen, W. J. J.; Dehaen, W.; Courtin, C. M.; Lagrain, B.; Boerjan, W.; Sels, B. F.; Energy Environ. Sci. 2015, 8, 1748.

12. Anderson, E. M.; Katahira, R.; Reed, M.; Resch, M. G.; Karp, E. M.; Beckham, G. T.; Román-Leshkov, Y.; ACS Sustainable Chem. Eng. 2016, 4, 6940.

13. Luo, H.; Klein, I. M.; Jiang, Y.; Zhu, H.; Liu, B.; Kenttämaa, H. I.; Abu-Omar, M. M.; ACS Sustainable Chem. Eng. 2016, 4, 2316.

14. Parsell, T.; Yohe, S.; Degenstein, J.; Jarrell, T.; Klein, I.; Gencer, E.; Hewetson, B.; Hurt, M.; Kim, J. I.; Choudhari, H.; Saha, B.; Meilan, R.; Mosier, N.; Ribeiro, F.; Delgass, W. N.; Chapple, C.; Kenttämaa, H. I.; Agrawal, R.; Abu-Omar, M. M.; Green Chem. 2015, 17, 1492.

15. Klein, I.; Saha, B.; Abu-Omar, M. M.; Catal. Sci. Technol. 2015, 5,3242 .

16. Li, C.; Zhao, X.; Wang, A.; Huber, G. W.; Zhang, T.; Chem. Rev. 2015, 115, 11559.

17. Li, S.-H.; Liu, S.; Colmenares, J. C.; Xu, Y.-J.; Green Chem. 2016, 18, 594.

18. Schutyser, W.; Renders, T.; Van den Bossche, G.; Van den Bosch, S.; Koelewijn, S.-F.; Ennaert, T.; Sels, B. F. In Nanotechnology in Catalysis; Van de Voorde, M.; Sels, B., eds.; Wiley-VCH: Weinheim, 2017, p. 537.

19. Rinaldi, R. In Lignin Valorization: Emerging Approaches; Beckham, G. T., ed.; Royal Society of Chemistry: London, 2018, p. 108.

20. Wang, X.; Rinaldi, R.; Energy Environ. Sci. 2012, 5, 8244.

21. Cao, Z.; Dierks, M.; Clough, M. T.; de Castro, I. B.; Rinaldi, R.; Joule 2018, 2, 1118.

22. Ferrini, P.; Rezende, C. A.; Rinaldi, R.; ChemSusChem 2016, 9, 3171 .

23. Chesi, C.; de Castro, I. B.; Clough, M. T.; Ferrini, P.; Rinaldi, R.; ChemCatChem 2016, 8, 2079.

24. Graça, I.; Woodward, R. T.; Kennema, M.; Rinaldi, R.; ACS Sustainable Chem. Eng. 2018, 6, 13408. 
25. Renders, T.; Van den Bosch, S.; Vangeel, T.; Ennaert, T.; Koelewijn, S.-F.; Van den Bossche, G.; Courtin, C. M.; Schutyser, W.; Sels, B. F.; ACS Sustainable Chem. Eng. 2016, 4, 6894.

26. Galkin, M. V.; Smit, A. T.; Subbotina, E.; Artemenko, K. A.; Bergquist, J.; Huijgen, W. J. J.; Samec, J. S. M.; ChemSusChem 2016, 9, 3280

27. Van den Bosch, S.; Schutyser, W.; Koelewijn, S.-F.; Renders, T.; Courtin, C. M.; Sels, B. F.; Chem. Commun. 2015, 51, 13158.

28. Goyal, G. C.; Lora, J. H.; Pye, E. K.; Tappi J. 1992, 75, 110.

29. Pan, X.; Gilkes, N.; Kadla, J.; Pye, K.; Saka, S.; Gregg, D.; Ehara, K.; Xie, D.; Lam, D.; Saddler, J.; Biotechnol. Bioeng. 2006, 94,851

30. Jääskeläinen, A. S.; Sun, Y.; Argyropoulos, D. S.; Tamminen, T.; Hortling, B.; Wood Sci. Technol. 2003, 37, 91.

31. Lindner, A.; Wegener, G.; J. Wood Chem. Technol. 1988, 8, 323.

32. Johansson, A.; Aaltonen, O.; Ylinen, P.; Biomass Bioenergy 1987, 13, 45.

33. Bozell, J. J.; Black, S. K.; Myers, M.; Cahill, D.; Miller, W. P.; Park, S.; Biomass Bioenergy 2011, 35, 4197.

34. Faix, O.; Lange, W.; Beinhoff, O.; Holz Roh-Werkst. 1984, 42, 245.

35. Decina, S.; Crestini, C. In Biorefinery: from Biomass to Chemicals and Fuels; Aresta, M.; Dibenedetto, A.; Dumeignil, F., eds.; De Gruyter: Berlin, 2012, p. 167.
36. Fengel, D.; Wegener, G.; Wood: Chemistry, Ultrastructure, Reactions; De Gruyter: Berlin, 1983, p. 132.

37. Mansfield, S. D.; Kim, H.; Lu, F.; Ralph, J.; Nat. Protoc. 2012, 7,1579 .

38. Yin, S. Y. In Methods in Lignin Chemistry; Yin, S. Y.; Dence, C. W., eds.; Springer-Verlag: Berlin, 1992, ch. 5, p. 217.

39. Yuan, T.-Q.; Sun, S.-N.; Xu, F.; Sun, R.-C.; J. Agric. Food Chem. 2011, 59, 10604.

40. Calvaruso, G.; Burak, J. A.; Clough, M. T.; Kennema, M.; Meemken, F.; Rinaldi, R.; ChemCatChem 2017, 9, 2627.

41. Ralph, J.; Hatfield, R. D.; J. Agric. Food Chem. 1991, 39, 1426.

42. Scanlon, J. T.; Willis, D. E.; J. Chromatogr. Sci. 1985, 23, 333.

43. Mestrelab Research; MestreNova 8.1.1.; Mestrelab, Spain, 2013.

44. Heikkinen, S.; Toikka, M. M.; Karhunen, P. T.; Kilpeläinen, I. A.; J. Am. Chem. Soc. 2003, 125, 4362.

45. Hu, K.; Westler, W. M.; Markley, J. L.; J. Am. Chem. Soc. 2011, $133,1662$.

46. Cheng, K.; Sorek, H.; Zimmermann, H.; Wemmer, D. E.; Pauly, M.; Anal. Chem. 2013, 85, 3213.

Submitted: July 17, 2018 Published online: November 26, 2018 